\title{
El sistema uninominal en la historia electoral argentina ${ }^{1}$
}

\author{
Sabrina Ajmechet ${ }^{2}$ \\ Luciano de Privitellio ${ }^{3}$
}

\begin{abstract}
Resumen
Este artículo se centra en el estudio de las dos leyes electorales que establecieron el sistema uninominal en la historia argentina: la de 1902 bajo el gobierno de Roca y la de 1951 con Perón. Inscribiéndose en un enfoque renovado sobre el análisis de las elecciones y sus reglas de juego, se analizan los diseños electorales de ambos momentos como expresiones de un conjunto de valores acerca del sentido de la representación política. Se buscarán explicar las miradas que se expresaron en cada coyuntura sobre las definiciones de lo político: qué era la sociedad y cómo debía ser gobernada. Así se mostrará cómo el mismo sistema electoral utilizado en las elecciones de 1904 y luego en las de 1951 y 1954 tuvo concepciones, objetivos y consecuencias completamente disímiles. Mientras que Roca y su ministro del interior, Joaquín V. González, buscaron representar políticamente los intereses económicos que se expresaban en la sociedad, la intención de Perón fue implementar un sistema que le permitiera construir un congreso unánime.
\end{abstract}

Palabras Clave: Historia Política Argentina - Elecciones - Leyes Electorales - Roquismo - Peronismo

\begin{abstract}
Summary
This article focuses on the study of the two electoral laws that established the uninominal system in Argentina: the first one was in 1902 under the government of Roca and the second one was in 1951 when Perón was President. Enrolling in the recent electoral studies, with a renewed way of analysing the elections and its rules, we study the electoral designs of both moments as expressions of a set of values that define political representation. In this article we seek to explain the ideas about the political world that were expressed at each occasion. By this mean, we will see that even though the same electoral system was used in the elections of 1904 and in 1951 and 1954, their conceptions, objectives and consequences were completely different. While Roca and his Minister Joaquin V. Gonzalez tried to give politica representation to the economic interests that were expressed throughout the society, Perón's intention was to implement a system that would allowed him to build a unanimous Congress.
\end{abstract}

Keywords:Political History of Argentina Elections - Electoral Laes - Roquism Peronism

\footnotetext{
${ }^{1}$ Trabajo recibido el 29/03/2016. Aceptado el 31/05/2016.

${ }^{2}$ Facultad de Ciencias Sociales de la Universidad de Buenos Aires. Universidad Nacional de San Martín. Contacto: ajmechet@gmail.com

${ }^{3}$ Investigador del Consejo Nacional de Investigaciones Científicas y Técnicas. Universidad Nacional de San Martín. Contacto: lprivite@gmail.com
} 


\section{Introducción}

La historia electoral argentina, desde la constitución del Estado en 1853 hasta nuestros días, se caracterizó por el uso de tres grandes sistemas. Inicialmente, un régimen de mayoría también denominado de lista completa, que fue utilizado entre 1853 y 1912. Luego, con la famosa reforma promovida por el presidente Roque Sáenz Peña, el sistema fue sustituido por uno de mayoría y minoría o de lista incompleta. ${ }^{4}$ Por último, en 1962 el presidente José María Guido envió el proyecto que introdujo la representación proporcional que, con algunas modificaciones, es el que aún rige nuestro régimen electoral. Sin embargo, esta historia que es correcta en términos generales olvida que en tres elecciones nacionales, 1904, 1951 y 1954 -las dos primeras incluyeron la elección de presidente y vice- se utilizó una modalidad notoriamente diferente a todas las anteriores, conocida como uninominal por circunscripción. De dudosa constitucionalidad -en todos los casos se discutió si se adecuaba al imperativo constitucional que debía considerar a las provincias y la Capital Federal como distritos electorales de un solo Estado- ${ }^{5}$, este sistema fue aprobado por primera vez en 1902 y derogado en 1905 y, por segunda ocasión, en 1951, para ser derogado luego de la caída de Juan Domingo Perón en 1955. Con varios antecedentes en las legislaciones electorales provinciales (ya sea como sistema único o en regímenes mixtos), en cambio se trata de una modalidad extraña para la legislación nacional.

Las investigaciones sobre leyes y sistemas electorales han cobrado un fuerte impulso entre los historiadores a partir de la publicación del texto ya clásico de Pierre Rosanvallon sobre el sufragio universal en Francia. ${ }^{6}$ Aunque estos trabajos mantienen interrogantes más estudiados, que apuntan por ejemplo a dar cuenta de las conveniencias políticas de los partidos en función de los sesgos de cada sistema, el trabajo de Rosanvallon ha permitido añadir otro conjunto de interrogantes, menos vinculados a la inmediatez del puro interés. Un diseño electoral, según el autor, expresa un conjunto de valores, de visiones sobre el objeto y el sentido

\footnotetext{
${ }^{4}$ La ley 8871 de 1912 introdujo este sistema tanto para la elección de diputados nacionales como para la de electores de presidente y vice. En 1936, fue aprobada en el Congreso una polémica reforma enviada por el presidente Agustín P. Justo, que reintrodujo el régimen de mayoría para el caso de los miembros de los colegios electorales.

${ }^{5}$ Constitución de la Nación Argentina. Originalmente artículo 33, hoy se mantiene en el artículo 45.
}

${ }^{6}$ Rosanvallon, (2007). 
de la representación política, que, en conjunto, dan cuenta de lo que denomina lo político. Lo político es entendido simultáneamente como un campo y un trabajo en el que una población aprehende y da sentido al mundo, incluyendo, especialmente, la propia comunidad de referencia. ${ }^{7}$ Por esa razón, una ley electoral no es solo un artilugio técnico que da cuenta de un modo más o menos transparente de la representación de una sociedad definible a priori en términos analíticos, sino que es en parte a través de ella que se define cuál es la característica de esa sociedad, cuáles son sus componente y, en consecuencia, cuáles serían las mejores formas de representarla y gobernarla. En cierto sentido, la representación no constituye un fenómeno que sigue a la existencia de una sociedad que se revela de modo objetivo e igual para todos, sino que es a través de su propio trabajo que el proceso de representación define qué y cómo es la sociedad que debe ser representada. De forma más o menos explícita según los casos, la representación -que incluye una concepción de la sociedad y los mecanismos más efectivos para canalizar esa representación- y la naturaleza del poder legítimo están en el centro de los debates de toda ley electoral. Incluso cuando sea posible argumentar que determinado sistema ofrece un sesgo a favor del interés de tal o cual grupo, es la propia idea de ese interés la que se recorta sobre una visión de la sociedad y del poder legítimo. Lo que cada actor considera su interés es inescindible de la forma en que se imagina la representación.

En este texto nos proponemos estudiar los dos períodos en los que se aprobó y utilizó el sistema de circunscripción uninominal. Intentaremos explicar las razones más inmediatas que llevaron a los legisladores a aprobar ambas leyes. Lo haremos considerando el sistema de ideas, visiones y valores que construyeron sus argumentos y definieron sus opciones. La coincidencia en la prescripción de circuitos uninominales y la apelación al antecedente de 1902 durante el debate de 1951 no significa que las leyes fueran idénticas, ni siquiera parecidas. Evidentemente, tampoco lo fueron los escenarios políticos en los que este sistema venía a implantarse. Pero, sobre todo, diferían notoriamente los objetivos y valores que, en cada caso, los reformistas buscaron implantar a través del circuito uninominal. Un mismo sistema se insertó sin embargo en dos universos de relaciones y de creencias, dando lugar a dos artefactos diversos.

\footnotetext{
${ }^{7}$ Rosanvallon, (1992).
} 


\section{La reforma de 1902, la primera vez que se implementó el sistema uninominal}

En 1902, la estructura de alianzas que había llevado al roquismo al poder había saltado por los aires. Esta profunda crisis, iniciada a mediados del año anterior, cuando el debate sobre la unificación de la deuda había terminado con una pelea entre Roca y Pellegrini, parecía no alcanzar sus límites. Una de las manifestaciones más evidentes de la situación era la acelerada fragmentación de las frágiles estructuras partidarias y la aparición de otras nuevas que desafiaban un ya inestable equilibrio de fuerzas. En este marco, el reclamo de una reforma que restableciera la verdad electoral aparecía como uno de los temas centrales de discusión, especialmente entre los críticos del gobierno, que eran muchos. ${ }^{8} \mathrm{Y}$ todo esto se agravaba porque, como era habitual, a dos años de expirar el mandato presidencial, la cuestión de la sucesión comenzaba a instalarse en el centro de las preocupaciones. Era evidente que Roca, muy debilitado, no estaba en condiciones de imponer su juego, pero tampoco parecía razonable esperar que no participara activamente del mismo.

Según sugiere Martín Castro, existe una relación directa entre esta crisis y la propuesta de una reforma. ${ }^{9}$ Sin descartar esta hipótesis, no parece tan sencillo establecer los vínculos causales entre el interés de Roca por controlar su sucesión y los contenidos específicos de la ley, más aún cuando la misma se aplicaría recién en 1904, es decir, cuando la cuestión sucesoria debía estar al menos medianamente resuelta. Por un lado, la propuesta no gozó de un apoyo entusiasta, ni siquiera entre los propios aliados del presidente, aunque Roca consiguió mediante una calculada presión los votos necesarios para su aprobación, no sin antes haber tenido que aceptar numerosos cambios sobre el texto original. Por otra parte, la aplicación de un régimen de circunscripción uninominal implicaba muchos riesgos para los partidos, a la vez que hacía desaparecer de un plumazo uno de los terrenos en los que habitualmente se ensayaban acuerdos entre ellos.

Según la voz oficial, una de las ventajas de este nuevo régimen es que contemplaba un reclamo que había comenzado a aparecer en los años setenta y que una vez que el PAN se convirtió en el partido hegemónico, se había vuelto aún más intenso: el de la representación de las

\footnotetext{
${ }^{8}$ Botana, (1985) y Castro, (2012).

${ }^{9}$ Castro, (2012).
} 
minorías. Según los voceros oficiales, con el ministro del interior Joaquín V. González a la cabeza, la diversidad espacial de la distribución de las circunscripciones uninominales produciría naturalmente la promoción de legisladores con posiciones políticas igualmente diversas.

Aún no es del todo claro cuál podría haber sido el objetivo coyuntural de Roca al promover la reforma, salvo dinamitar un sistema electoral que habilitaba ciertas prácticas muy instaladas en las costumbres ${ }^{10}$. Aún así, la pura conveniencia política no parece ofrecer una única causa sólida para la iniciativa.

\section{El sentido de una reforma}

Si bien durante las sesiones del Congreso se trataron diversos puntos que formaron parte del proyecto de ley, entre ellos las modalidades del derecho de voto para los extranjeros, la naturaleza secreta o pública del voto y, sobre todo, las formas de confección de un nuevo padrón permanente que sería acompañada por un documento electoral, ${ }^{11}$ el eje del debate se concentró en la principal innovación de la ley: la circunscripción uninominal. Esto sucedió así porque para el autor y principal defensor de la ley, el ministro González, este cambio condensaba buena parte de la apuesta de la reforma. En efecto, para González el nuevo sistema permitiría acabar con lo que, según su diagnóstico, constituía el principal problema de la política argentina, lo que hoy se definiría como una crisis de representación

«Hemos llegado a convencernos igualmente que existe una profunda antinomia, una profunda contradicción, de que habla un filósofo político, entre la constitución social y la constitución política. Las fuerzas sociales que dan existencia real a nuestra cultura presente, no tienen una representación formal en la ley, en cuya virtud deba hacerse práctica, o deba traducirse en forma práctica por medio del mandato del legislador». ${ }^{12}$

No es extraño que todos quienes han estudiado el reformismo llamen la atención sobre esta frase, ya que la misma resume de modo ma-

\footnotetext{
${ }^{10}$ De Privitellio, (2012).

${ }^{11}$ De Privitellio, (2012).

${ }^{12}$ González, (1903): 21.
} 
gistral uno de los pilares del imperativo que atravesó a la opinión durante el paso del siglo XIX al XX. ${ }^{13}$ La política ya no representaba a la sociedad y, en consecuencia, giraba como una rueda loca capaz de destruir el camino hacia el progreso.

González conceptualizaba a los partidos como meras instancias intermedias entre el representante y el representado y, por tanto, su presencia tendía más a confiscar que a canalizar una representación legítima. La circunscripción uninominal, por el contrario, creaba un mecanismo representativo legítimo y transparente que, por esa razón, permitiría subsanar la crisis de la política. Pero, a diferencia de los defensores de los partidos, esa transparencia no sería el resultado de la presencia de un mecanismo institucional específico, sino de la propia dinámica social.

El razonamiento comenzaba identificando la circunscripción con una comunidad social de dimensión local. Para González, la circunscripción no implicaba un recorte del territorio basado en criterios meramente abstractos -incluyendo entre ellos el principio aritmético- sino una comunidad viva y realmente existente. ${ }^{14}$ Esta asociación es la clave de la reforma, porque esa comunidad debía constituirse como el objeto de la nueva trama representativa. A su vez, esa comunidad se estructuraba a partir de dos variables: por un lado, alrededor de algún tipo de actividad económica predominante, capaz de dar organicidad a la sociedad local; por otro, de un sistema de jerarquías sociales, en última instancia determinadas por esa misma actividad. De esta forma, era la propia heterogeneidad del mapa productivo del país lo que garantizaría el pluralismo de la Cámara y la representación de las minorías. La pluralidad política sería el resultado natural de una más elemental y relevante pluralidad social.

\footnotetext{
${ }^{13}$ Ciertamente, el reformismo de comienzos de siglo no siempre oponía la imagen de una sociedad sana a una política enferma. La propia sociedad era también objeto de diagnósticos mucho menos optimistas, Zimmermann, (1995). Sin embargo, cuando se trataba de analizar reformas electorales -lo mismo sucede durante los debates de 1911-esa idea es predominante. $\mathrm{Al}$ respecto, Natalio Botana ha sugerido la influencia del regeneracionismo español, Botana, (1985).

${ }^{14}$ Las críticas a las concepciones estrictamente aritméticas de la representación no eran una novedad y tampoco un fenómeno específicamente argentino, sino propio de buena parte de occidente, Rosanvallon, (2007). Si bien la pura aritmética sustentaba la concepción igualitaria de la idea de ciudadanía, la necesaria abstracción que suponía la idea de ciudadano que se desprendía de ella era objeto de fuertes críticas en nombre de concepciones organicistas de la ciudadanía y de la representación. Las clases sociales de los socialistas como la comunidad local de González son ejemplos de esta tendencia.
} 
Si la circunscripción garantizaba el tan reclamado pluralismo capaz de dar lugar a la representación de las minorías, también aseguraba la transparencia de la representación. Según González, la circunscripción favorecería el conocimiento directo entre candidatos y votantes, como resultado no de una instancia artificial política sino de la propia dinámica social, lo cual a su vez daba como resultado una representación absolutamente transparente. En este sentido, lo social, definido en términos de una práctica económica y de un sistema de sociabilidad y jerarquías que se ordena a su alrededor, se convierte en el objeto central de la representación. Es decir, predomina una concepción de la representación como versión en escala de la propia sociedad, una noción de origen británica que está en el centro de la reforma roquista. ${ }^{15}$

Ahora bien: ¿Cómo se transforma la representación social en un orden político? Y, a su vez, ¿Cómo se convierte el pluralismo social en pluralismo político? El problema no es menor, toda vez que la cuestión de las minorías, tal como se define en los debates de la época, no admite una resolución exclusiva en el plano de lo social. Se trata de un imperativo político que reclama una solución en el plano político. Como sucede en buena parte del siglo XIX, es el parlamento la institución clave ${ }^{16} \mathrm{y}$ será en él donde se opere la alquimia. En efecto: es en el desarrollo de la propia práctica legislativa, y no en la sociedad civil, donde se constituye aquello que González llama partidos.

El partido al que elogia no es una organización destinada a ganar elecciones -eso, como vimos, corresponde a la sociedad local reconocida por la circunscripción- sino más bien un agrupamiento de diputados en función de la opinión sobre uno u otro tema. Esto último es crucial: no se trata de organizaciones estables, sino de tendencias de opinión vinculadas a temas específicos. Para González, el partido electoral, más allá de su origen, siempre constituye una confiscación de la voluntad con la consiguiente opacidad representativa. Es en el parlamento donde los intereses locales se convierten en propuestas políticas; de esta forma se cierra el círculo de la formación de una representación a la vez sólida, transparente y plural. El Congreso es el lugar de la deliberación y de los acuerdos -siempre transitorios- por excelencia, el lugar donde la representación sustentada en lo social se convierte en política.

${ }^{15}$ Biagini, (1998); Morgan, (2006); Pitkin, (1985); Romanelli, (1997); Rosanvallon, (2007). 


\section{El sistema uninominal en el peronismo: la búsqueda de la unanimidad}

El 11 de julio de 1951 un parlamento con mayoría peronista aprobó por segunda vez un régimen de circunscripción uninominal para la elección de diputados nacionales. ${ }^{17}$ No era este el primer cambio institucional de magnitud aprobado por el peronismo que afectaba a la política, por el contrario, para entonces ya se había aprobado el sufragio femenino, la ley de partidos políticos y la reforma de la Constitución Nacional. ${ }^{18}$ Sin embargo, la iniciativa de una reforma electoral fue presentada en forma sorpresiva y tratada sobre tablas en la sesión de diputados del 5 y 6 de julio y fue aprobada sin discusión en las comisiones y sin que mediara un debate público previo. ${ }^{19}$

La sorpresa era doble. Por un lado, nada indicaba que un proyecto de reforma electoral fuera a ingresar en el Parlamento. Por otro, más aún sorprendió la elección de la circunscripción. Desde el debate por la reforma de 1912, cuando González había insistido en las bondades del sistema uninominal, solo algunas voces muy menores se habían alzado a favor de este sistema. Esto no implicó que desapareciera la cuestión electoral del debate público, que por el contrario ocupó un lugar central durante todos los años de entreguerras. Tampoco se descartó la crítica al sistema vigente desde 1912 en nombre de la representación de intereses económicos, pero las concepciones corporativistas y la representación funcional que se difundieron con fuerza desde los años veinte reemplazaron al complicado mecanismo centrado en lo local imaginado por González.

Luego de la elección de 1946, durante los primeros cinco años en el gobierno, el capital político del peronismo, de por sí abundante, no dejó de crecer. Perón tuvo un gran margen de maniobra para utilizar los resortes del gobierno para aumentar su poder personal y fortalecer a su partido. ${ }^{20}$ Este proceso incluyó una serie de importantes reformas, desti-

\footnotetext{
${ }^{16}$ Hobsbawm, (1994); Mosse, (2005); Romanelli (1997); Schmitt, (1990).

${ }^{17}$ En este caso, a diferencia de la ley de 1902, no incluía electores de presidente y vice, ya que la reforma constitucional de 1949 había eliminado este sistema, reemplazado por uno de elección directa con toda la Argentina como distrito único.

${ }^{18}$ Ajmechet, (2012); Ajmechet, (2015b).

${ }^{19}$ Ajmechet, (2015a).

${ }^{20}$ El problema de la relación Estado-gobierno-partido durante el peronista ha sido trabajado ampliamente Plotkin, (1994); Da Orden y Melón Pirro, (2011); Mackinnon, (2002) y Prol, (2012), entre otros.
} 
nadas todas ellas a adaptar las instituciones del Estado y de la política a las concepciones de Perón y del peronismo en general. ${ }^{21}$ La ley electoral resultó ser una pieza clave en esta ambiciosa apuesta.

Pese a esta fortaleza y a los importantes niveles de control político con los que contaba Perón, 1951 fue un año difícil para el gobierno. La bonanza material de la primera presidencia comenzaba a declinar. En enero estalló la huelga ferroviaria, que desgastó la relación con un sector importante del sindicalismo y demostró que los únicos gremios autorizados para la acción política eran aquellos agrupados dentro de la Central General de Trabajadores, convertida en una de las ramas del Partido Peronista. Para frenar lo que ya era caracterizado como una crisis, el gobierno consideraba necesario tomar medidas antipopulares que podían llegar a tener repercusiones negativas en los votantes del peronismo, como el recorte del gasto público y la regulación de la suba de los salarios. ${ }^{22}$

Sin embargo, los problemas no eran solo esos. Al parate económico y los conflictos sindicales, se sumaban las críticas de la oposición y las luchas dentro del Partido Peronista. Desde comienzos de año, se expresaron fricciones entre los peronistas producto de la selección de las candidaturas para la elección, ya que era necesario definir quiénes competirían por los cargos ejecutivos y legislativos locales y provinciales, como así también quién acompañaría a Perón en la fórmula presidencial. La competencia por ocupar lugares en las listas reveló la persistencia de diferencias dentro del oficialismo, que hasta unos meses antes parecían haber desaparecido. Por otro lado, los partidos opositores caldearon aún más la tensa situación política. En todos los ámbitos posibles, pronunciaron acusaciones sobre las prácticas autoritarias del gobierno que tenían como ejes el cierre y la expropiación del diario La Prensa, la expulsión de dos diputados de la Unión Cívica Radical de la Cámara bajo la figura del desacato y la creciente dificultad que enfrentaban las fuerzas de la oposición para realizar actividades proselitistas. Finalmente, en las Fuerzas Armadas las tensiones también fueron en aumento. Este no era un tema menor, ya que para Perón constituía una de las bases centrales de poder que reclamaba por eso una estricta atención. ${ }^{23}$

\footnotetext{
${ }^{21}$ Ajmechet, (2015b).

${ }^{22}$ Gerchunoff y Antúnez, (2002).

${ }^{23}$ Potash (1981); Rouquie, (1982).
} 
El gobierno descontaba que los futuros comicios se producirían en un clima conflictivo, posiblemente con la profundización de huelgas y de actividades sediciosas. Así lo reconocía en el Plan Político año 1951/ Directivas Generales, donde impartía dos series de instrucciones diferentes según se calificara a la campaña proselitista como «una situación normal o una anormal» ${ }^{24}$. Esta preocupación se mostraría acertada poco tiempo después, el 28 de septiembre, con el intento de golpe del general Benjamín Menéndez, que terminó generando que las elecciones se llevaran a cabo bajo la figura del estado de guerra interna, una innovación de la Constitución de 1949.

En este contexto, en el que el fortalecimiento del poder personal de Perón se superponía con -y en parte provocaba- una creciente tensión política, el proyecto (elaborado por los diputados Héctor Cámpora, Natalio Trebino, Juan de la Torre, Angel Miel Asquía, José Emilio Visca, Luis Atala, Pedro Tilli, Luis Armando Roche y Oscar Albrieu) fue presentado en la Cámara de Diputados. El proyecto introducía numerosas modificaciones, pero la novedad más importante fue el establecimiento del sistema uninominal por circunscripción.

Para el peronismo, el sistema de mayoría y minoría de la ley Sáenz Peña, utilizado en los comicios de 1946 y 1948, traía problemas en dos planos cruciales. Por un lado, garantizaba a la oposición una representación cercana al tercio de las bancas; por otro, resultaba inconveniente a la hora de concentrar el poder de decisión de las candidaturas en manos de Perón. Es evidente que en un escenario político altamente polarizado y en el que a diferencia de 1902 operaban partidos electorales, el sistema de lista ya no funcionaba como espacio para construir acuerdos políticos. No era necesario que así fuera, ya que la reforma Sáenz Peña de todos modos garantizaba la promoción de diputados por la minoría. Pero el régimen de lista abierta, que permitía las tachaduras, más la modalidad de escrutinio que seguía siendo por candidato individual y no por lista o partido, alentaban la expresión y canalización de disidencias dentro de cada partido. Lo que en el 1900 podía ser una cualidad virtuosa del sistema, medio siglo más tarde no era sino un inconveniente. Perón podía imponer candidatos y ahogar las disidencias a la hora de consagrar candidaturas, pero no podía evitar que los electores tacharan alguno de estos, algo que siguió sucediendo en las elecciones de 1946 y 1948.

${ }^{24}$ Luna, (2000): 487. 
Las tensiones internas del peronismo no eran un problema menor. Perón había llegado a la presidencia con el apoyo de numerosos partidos políticos, entre los cuales se destacaban por su importancia y su alcance nacional el Partido Laborista y la Unión Cívica Radical Junta Renovadora. Desde el principio, se hizo evidente que lo único que unía a estas fuerzas era su apoyo a Perón. De modo inevitable, las diferencias entre laboristas y renovadores rápidamente se tradujeron en fuertes disputas.

Dos semanas antes de asumir como presidente, Perón realizó un llamado a la unidad entre sus seguidores y ordenó la inmediata disolución de los partidos que habían sostenido su candidatura. En aquel momento comenzó el período de constitución del Partido Único de la Revolución Nacional, que culminaría en 1947 con la creación del Partido Peronista. Pese a la disolución formal de los partidos, los conflictos entre sus miembros siguieron existiendo. En los casos más extremos, como el de las provincias de Santa Fe y de Mendoza, se llegó a la creación de bloques parlamentarios divididos e, incluso, se presentaron a elecciones provinciales escisiones del peronismo, como el Partido Obrero de la Revolución y el Partido Peronista Laborista. ${ }^{25}$ Perón recurrió entonces a la legislación para bloquear este problema. La sanción de la ley de Partidos Políticos en 1949 eliminó de modo drástico la posibilidad de convertir los disensos internos en candidaturas, ya que cualquier nuevo partido debía esperar tres años desde su creación para poder competir en elecciones, una eternidad en términos políticos. ${ }^{26}$

Un modo complementario de solucionar los enfrentamientos entre los miembros del partido fue la selección de candidaturas. Por ejemplo, en la provincia de Buenos Aires, la Carta Orgánica de 1947 estipulaba que tanto las autoridades como la candidaturas a puestos electivos serían elegidos por el voto de los afiliados. Pero a partir de 1948 esta situación cambió: todos ellos fueron elegidos directamente por el Consejo Superior. Al momento de reformarse la ley electoral, el peronismo ya había centralizado su conducción y la toma de decisiones mediante la modificación de sus costumbres partidarias y también mediante la utilización de la ley nacional de partidos políticos. ${ }^{27}$ Pero siempre quedaba abierta la posibilidad de expresar disidencias en el cuarto oscuro. Aun-

\footnotetext{
${ }^{25}$ Prol, (2002) y Garzón Rogé, (2012).

${ }^{26}$ Ajmechet, (2015a).

${ }^{27}$ Aelo y Quiroga, (2006) y Ajmechet, (2015).
} 
que no alcanzara para hacer caer una candidatura, manifestaba públicamente que esas disidencias existían, poniendo en jaque a la idea de un movimiento monolítico detrás de un líder. En cambio, la promoción de un único candidato por distrito, eliminaría de un plumazo toda posibilidad de expresar disensos. Como veremos más adelante, el diseño de las boletas sumó más aún a la concreción de este objetivo.

Además de disciplinar a los propios peronistas, el sistema uninominal tendría como consecuencia previsible un sustancial aumento de la proporción de los diputados oficialistas. En principio, esto también servía para disciplinar a su partido, ya que por un lado podía acotar la relevancia de alguna eventual disidencia en el recinto y, por otro lado, la promoción de un mayor número de diputados ofrecía mayores posibilidades para sostener equilibrios. Pero, sobre todo, la nueva ley amenazaba con reducir considerablemente la presencia institucional de la oposición que, si bien no tenía capacidad propia ni para impulsar ni para frenar proyectos legislativos, utilizaba sus bancas en el Congreso para criticar con dureza al gobierno. En el contexto de un partido que alcanzaba cerca de los dos tercios de los votos, un sistema de circunscripciones uninominales podía terminar en una situación inédita para la Argentina del siglo XX: una cámara de diputados con una representación unánime seleccionada, además, por una sola persona o por un pequeño grupo bajo su exclusiva supervisión.

Por supuesto, la oposición radical advirtió inmediatamente este peligro y así lo denunció, pero el oficialismo no solo no se sintió afectado por esta acusación, sino que definió las bondades de ese eventual resultado. Solo durante el transcurso del debate -tal vez para quitar argumentos a los sectores unionistas de la UCR quienes ya fomentaban la abstención electoral, posición que defenderán poco después en la Convención Nacional de agosto- el peronismo decidió realizar una concesión. La palabra concesión no la utilizamos en forma arbitraria: fueron los propios legisladores oficialistas quienes definieron este cambio como un regalo del Perón a los opositores. ${ }^{28}$ La medida consistió en modificar en

\footnotetext{
${ }^{28}$ «Frente al reconocimiento de los señores diputados de la oposición de que no habría posibilidades de banca para ellos, hemos creído que era indispensable que aquí se levantara la voz de la oposición, aunque no sea por derecho constitucional, porque la Constitución exige la pluralidad de sufragio, ni por los derechos que pueda darse un pasado histórico en materia electoral. Queremos que sea por la magnanimidad de Perón» (José Emilio Visca, DSCD, 05 y 06/07/1951, pp. 1040-1041). Sobre la UCR y la convención de agosto de 1951, se puede consultar el libro de García Sebastiani, (2005): 240-241.
} 
parte el sistema, aunque solo en los cinco distritos más importantes del país, para que los dos candidatos que hubieran obtenido la mayor cantidad de sufragios sin haber ganado su circunscripción fueran promocionados a la Cámara. ${ }^{29}$ De esta manera, aún en el caso de queel peronismo ganara todas las circunscripciones del país, el radicalismo podría disponer de diez diputados. Una modificación que, por cierto, no fue muy bien recibida por la oposición.

\section{El conductor y la voluntad general}

El peronismo introdujo una importante cantidad de novedades en la cultura y los lenguajes políticos. Sin dudas, uno de los más relevantes fue su concepción del poder, de su legitimidad y del lugar de los comicios en ella. De un modo más elaborado en los discursos y notas luego reunidos en Conducción Politica y de una forma menos sistemática pero no por eso menos poderosa en afiches, ilustraciones, textos de propaganda, cancioneros y demás, la clave de esta mirada se concentró en la figura del conductor: ${ }^{30} \mathrm{~A}$ través de ella, no se trató simplemente de dar cuenta de un liderazgo más o menos poderoso. Alrededor de la figura del conductor se organizó una visión tan profunda como exitosa de lo político.

${ }^{29}$ «Para la elección de diputados nacionales, los distritos se denominarán circunscripciones; los electores de cada circunscripción elegirán a pluralidad de sufragios, un diputado al Congreso. El número de candidatos de Catamarca, Corrientes, Jujuy, Mendoza, La Rioja, Salta, San Juan, San Luis y Tucumán será igual al de diputados que les corresponda elegir. El número de circunscripciones de la Capital Federal, Buenos Aires, Santa Fe, Córdoba y Entre Ríos, será igual al de diputados que les corresponda elegir, menos dos. Estos cargos, excedentes serán discernidos a los dos candidatos que hubieran reunido mayor cantidad de sufragios y que no resultaren electos en sus respectivas circunscripciones» (Art. 46 de la ley $14032 / 51)$.

${ }^{30}$ La idea de pensar el liderazgo de Perón como el de un conductor se encuentra presente en gran parte de la bibliografía. Solo a modo de ejemplo: Fernández Vega, (2005); Plotkin, (1994); Halperín Donghi, (1993). Pero, además, también era pensado de este modo por el propio Perón, tal como se desprende de sus clases de Conducción Politica, Perón, (1951). Desde la perspectiva del peronismo, la sociedad se ordenaba en una jerarquía binaria, desde el conductor hasta las masas. Era un sistema de fines y propósitos en el cual lo inferior servía a lo superior y lo superior dirigía y guiaba a lo inferior. Eran funciones desiguales y no intercambiables. Cada uno, desde su lugar, participaba en la formación del orden social y político. En esa organización, con sus distintas partes, así como el alma rige al cuerpo, existía una cabeza que dirigía y guiaba a las masas hacia el bien común. Este era el conductor, que daba los lineamientos generales para que los auxiliares intermedios se ocuparan de hacer de la masa inorgánica una sociedad ordenada y obediente, Perón, (1952). 
La conducción politica define una forma de autoridad virtuosa que, aunque no siempre se presenta en la realidad, cuando lo hace proyecta esa virtud a la totalidad del cuerpo político, definido habitualmente como una masa. En efecto, solo una masa bien conducida adquiere las valencias positivas de las que carece por sí sola. Por tanto, según este esquema, el problema central de la política consiste en cómo identificar a ese conductor. Se trata de un problema porque, tal como se define en esas mismas notas $-\mathrm{y}$ fue repetido una y otra vez por los legisladores y la publicidad peronista- la capacidad para la conducción política constituye una cualidad innata. Asociada con las cualidades propias del arte, se trata de un atributo personal del que solo disponen algunos individuos extraordinarios y que es, en esencia, intransferible. ${ }^{31} \mathrm{Y}$, por supuesto, ninguna instancia institucional puede producir a un conductor, incluyendo entre esas instituciones al sufragio. Por esa razón, en 1951 Perón podía decir que en 1946 había ganado las elecciones porque el pueblo obedeció a su $o r$ den: para el momento de los comicios él ya era el conductor del pueblo argentino y la elección operó apenas como un modo más de reconocer esta situación. ${ }^{32}$

De este modo, las elecciones dejaron de ser el momento en el que cada elector decidía con su razón su opción política entre una oferta múltiple -tal como lo consagró la reforma Sáenz Peña sobre todo a partir de la introducción del cuarto oscuro- ${ }^{33}$ para convertirse en un ritual de reconocimiento de un liderazgo político preexistente. Las elecciones no producían la representación, ya que esta existía previamente como encarnación en la figura del conductor. ${ }^{34}$ Por eso, incluso las elecciones par-

\footnotetext{
${ }^{31}$ Sobre la relación entre arte y política en general y especialmente sobre la visión del líder político como artista ver La estética nazi. Un arte de la eternidad de Éric Michaud (Michaud, (2009)), especialmente los capítulos 1 y 2. Se puede encontrar una reflexión sobre la relación entre la imagen del conductor y el procesamiento de las igualdades y desigualdades políticas en «De igualdades y desigualdades: elecciones y poder en el imaginario político argentino» (De Privitellio, (2013)).

32 (...) me fue posible, el día anterior a las elecciones, dar una orden que al día siguiente todos cumplieron. Fue asi como ganamos las elecciones. Nuestros adversarios politicos, cuando nosotros dimos esa orden, se reían, pero después del escrutinio ya no se rieron tanto. (Perón, 1952, p. 206). ${ }^{33}$ Persello y De Privitellio, (2012), De Privitellio, (2011).

${ }^{34}$ Esta idea de un líder que encarnaba la voluntad del pueblo y que, al mismo tiempo, creaba la voluntad en el pueblo está trabajada por Pierre Rosanvallon en el capítulo «La democracia iliberal» del libro La democracia inconclusa. Historia de la soberanía del pueblo en Francia (Rosanvallon, (2006)). Allí habla de la modalidad encarnación de la representación política bajo la figura del cesarismo.
} 
lamentarias cobraban un sentido absolutamente plebiscitario en relación a la figura del líder. En cada una de las elecciones, el peronismo organizó su campaña alrededor de los candidatos de Perón, cuando se hablaba de ellos.

Sin embargo, esta concepción chocaba con un problema empírico. Si Perón era la voz única del pueblo, si era su encarnación, cada vez que se realizaba una elección se hacía evidente la existencia de un tercio de los electores que contrastaban esta situación. Lejos de expresar la unanimidad del pueblo detrás del conductor que encarna su voluntad, la elección exhibía un país dividido precisamente por su figura. Y, dado el sistema impuesto por la ley Sáenz Peña, el Congreso se convertía a su vez en un bullicioso vocero de esa tajante división. Fruto de una casualidad, ese tercio electoral aproximado se expresaba en el tercio de los diputados que la ley Sáenz Peña otorgaba a la minoría. Las elecciones, desde esta perspectiva, revelaban y producían una diversidad que el peronismo no quería reconocer.

Durante el debate por la reforma electoral, los argumentos centrales esgrimidos por los representantes peronistas fueron en parte calcos de los utilizados en 1902, sobre todo la ponderación de la cercanía entre elector y candidato en función de la reducción del espacio de producción del sufragio. ${ }^{35}$ Pero, a diferencia de ese precedente, en este debate nadie diagnosticó la existencia de una crisis de representación. La representación era un conflicto, dado que ella ya existía encarnada en la figura de Perón.

El problema, en cambio, era cómo construir un Congreso, en especial una Cámara de Diputados donde aún se sentaban algunos legisladores opositores, en consonancia con esa visión de la política. ${ }^{36} \mathrm{La}$ oposición lo advirtió muy rápidamente: el nuevo sistema amenazaba con la

\footnotetext{
${ }^{35}$ Por ejemplo, El voto por circunscripción traerá al seno del Congreso Nacional hombres interiorizados de las circunstancias en que se desenvuelve la vida del electorado que les ha conferido el mandato, y podrán entregar a la Cámara, el aporte inestimable de su conocimiento profundo de los problemas regionales. $\Upsilon$ más aún, favorece desde el punto de vista del contralor popular porque, negando desde ya la tesis sustentada de que este sistema implicaría una especie de mandato imperativo para los legisladores, no podemos ignorar la ventaja que representa para el electorado, que podrá ejercer más de cerca el contralor de los actos de sus representantes; (...) es innegable la ventaja que significa que el legislador se sepa más directamente observado por el pueblo que lo ba elegido. (Alejandro Giavarini, DSCS, 11/07/1951, p. 534)

${ }^{36}$ Del Bloque de los 44 radicales elegidos en 1946, al momento de discutir la ley electoral solo mantenían sus bancas 23 diputados.
} 
conformación de una Cámara unánime que en consecuencia actuaría naturalmente como un espacio de confirmación plebiscitario de las decisiones del presidente. El sistema uninominal servirá para consagrar la unanimidad oficial, sentenció Reynaldo Pastor, diputado por el Partido Demócrata. ${ }^{37}$ Los diputados peronistas no contrastaron esta acusación. En primer lugar, porque en el lenguaje del peronismo la balanza entre el conductor y las instituciones siempre debía inclinarse a favor del primero. ${ }^{38}$ Algunos incluso afirmaron lo contrario y elogiaron el nuevo sistema electoral porque permitía el triunfo del espiritu nacional mediante la construcción de la unanimidad. ${ }^{39}$ Para otros, si esa iba a ser la situación, no sería por la responsabilidad del nuevo sistema electoral, sino por decisión del electorado. ${ }^{40}$

Como se puede advertir, esta cuestión constituye una diferencia crucial con el clima de ideas de 1902. Para entonces, el problema del ingreso de las minorías en el parlamento, en un momento en el que los partidos modernos apenas estaban constituyéndose como tales, era uno de los imperativos más acuciantes. Medio siglo mas tarde, con partidos presentes, la cuestión de las minorías era para la bancada peronista un problema menor, cuando no una creación artificial de un régimen electoral nocivo. ${ }^{41}$ La definición del pueblo como una masa unánime, a la que se atribuía una voluntad única alrededor de una doctrina (inicialmente justicialista pero luego nacional a secas) se sumaba a la concepción de un

\footnotetext{
${ }^{37}$ Reynaldo Pastor, DSCD, 05 y 06/07/1951, p. 1019.

${ }^{38}$ Ajmechet, (2015).

${ }^{39}$ John William Cooke, DSCD, 5 y 6 de julio de 1951, p. 1028

${ }^{40}$ Si los señores diputados creen que no van a ganar en ninguna de las 168 circunscripciones en que estará dividida la República, allá ellos; será el pago de sus culpas, será que el pueblo argentino está comprendiendo en forma absoluta y definitiva qué es lo que interesa a la patria, y que en algunos aspectos ya lo señalara el hombre de la intransigencia, que jamás claudicó frente a los halagos del poder ni frente a las complacencias del adversario. (José Emilio Visca, DSCD, 5 y 6 de julio de 1951, p. 1041)

${ }^{41}$ Durante el debate del proyecto electoral, los peronistas caracterizaron a la minoría y a su rol de la siguiente forma: «(...) en la democracia pueblo significa mayoría (Oscar Albrieu, DSCD, 05 y 06/07/1951, p. 978)», «La función de las minorias es (...) tratar de mejorar lo que hace la mayoría, pero de ninguna manera suplantar en el gobierno a las mayorias porque si no se cae en la subversión. (Pablo Ramella, DSCNC, 15/02/1949, p. 168)» y «En la actualidad, con el sistema de voto restringido, las minorias tienen asegurado un numero determinado de representantes que es independiente de la cantidad de sufragios obtenidos en la elección. Esa representación no es justa, no es proporcional al número de votantes. (Vicente Bagnasco, DSCD, 05 y 06/07/1951, p. 1011)».
} 
conductor capaz de encarnar esa voluntad para eliminar cualquier virtud alrededor de la existencia de minorías parlamentarias.

«En el país hay unidad de ideales nacionales. Cuando los ideales doctrinarios sobre los puntos básicos de la estructuración nacional no están consolidados, es aceptable asegurar a las minorías, aún cuando fueran pequeñas, una representación que les permita hacer oír su opinión sobre esos puntos que hacen a la esencia de la vida del país. Pero cuando esos objetivos han sido superados, cuando la Nación, organizada como República federal, ha ido cumpliendo paulatinamente, sin detenerse, las aspiraciones de las provincias que la componen, anticipadas ya en 1853 por los diputados al Congreso General Constituyente, y que tan admirablemente han sido condensadas en el preámbulo de nuestra Carta Fundamental, a la que -necesario es reconocerlo- se le ha agregado el ideal peronista, ratificando la irrevocable decisión de constituir una nación socialmente justa, económicamente libre y políticamente soberana, entonces los partidos políticos sólo pueden desarrollar su acción dentro de un perímetro integrado por ideales comunes, diferenciándose sólo en los procedimientos para lograr su concreción. .»2

Una vez definidos los ideales nacionales ${ }^{43} \mathrm{y}$, sobre todo, identificados sus voceros, empezando por la figura del conductor, cualquier oposición quedaba relegada al exterior del campo político legítimo.

«Debemos continuar bregando con firmeza a fin de sortear el cúmulo de obstáculos, que a manera de valladar intentan contener el ímpetu progresista que Perón imprimió al país. Fuertes intereses de naturaleza foránea algunos, internos otros, sumados a la incomprensión, cuando no a la ignorancia de los más, constituyen un conglomerado minoritario en cuanto a su número, pero unidos en su acción negativa y disolvente, dispuestos a luchar por una bandera donde cabe toda la gama de colores menos el azul y blanco de nuestra enseña nacional; pero de poco ha de servir su obstinación.» ${ }^{44}$

\footnotetext{
42 Vicente Bagnasco, DSCD, 05 y 06/07/1951, p. 1015.

${ }^{43}$ La noción de un pueblo único e indivisible, depositario de una voluntad unánime, está muy lejos de ser una novedad en la cultura política argentina: Sabato, (2009); Persello y de Privitellio, (2009); Mustapic, (1984); Alonso, (2010); Padoán, (2002); Persello, (2006), entre otros.

${ }^{44}$ Vicente Bagnasco, DSCD, 05 y 06/07/1951, p. 1015.
} 
Desde la perspectiva peronista, la existencia de visiones alternativas no solo no era vista como necesaria sino que, incluso, era entendida como perjudicial. Y esto era cierto tanto para la esfera pública como para el parlamento. En tanto la voluntad general se encarnaba en un conductor, las instituciones -como el sufragio y el parlamento- como así también los agentes de la esfera pública -diarios, radios o asociacionestenían como función consagrar y amplificar esa voz. La irritación y el fastidio con el cual los peronistas se referían al gusto de los radicales por la discusión parlamentaria y la naturalidad con la cual solicitaban y aprobaban los cierre de debate, deben ser comprendidos no como un mero ejercicio de autoritarismo o una estrategia parlamentaria, sino también como la consecuencia de un modo de comprender la relación entre el pueblo uno y la expresión de su voluntad. En este esquema, la única deliberación posible la encarna el diálogo directo entre el conductor y su pueblo, sin ninguna clase de intermediación. El escenario por excelencia de esos diálogos era la plaza pública, un baño de multitud en el cual la unanimidad prima entre los varios aspectos teatrales de ese ritual. ${ }^{45} \mathrm{El}$ Congreso debía adaptarse a esta nueva figura de la voluntad general y la reforma electoral de 1951 fue la respuesta a este imperativo. Su rol debía ser convertir en leyes las decisiones del Poder Ejecutivo y, al mismo tiempo, operar como un lugar más (al igual que la plaza, la escuela, los periódicos) en el que se escenificaba la unanimidad. Sin importar donde se expresara, las voces plurales eran la huella de una división inaceptable y peligrosa para la propia existencia de la comunidad política. Por eso, para el peronismo nada había de negativo en una representación parlamentaria unánime.

Pero se trataba de una virtud peligrosa. Como hemos señalado, durante 1951 las tensiones políticas eran intensas y el proceso de centralización del poder y el bloqueo a las expresiones de cualquier voz no

\footnotetext{
${ }^{45}$ La concepción de la deliberación política como un dialogo entre masa y líder no era simplemente una concepción libresca. El famoso Cabildo Abierto del 22 de agosto de 1951 donde la multitud exigió la candidatura de Eva Perón para la vicepresidencia demuestra que podía convertirse en una práctica deliberativa, más allá de que luego la candidatura fuera descartada. Todavía en 1974, la agrupación Montoneros preparó su presencia en la plaza para el 1 de mayo bajo la premisa de un diálogo entre el pueblo y su líder, en el que el pueblo exigiría la depuración de su gobierno. Tampoco en este caso el diálogo fue muy eficaz, pero nuevamente este es un problema secundario frente a la forma de comprender dicho intercambio. Véase por ejemplo esta concepción en la revista El Peronista, Lucha por la liberación (19/04/1974, p. 1-2) y las formas de ese dialogo en Perón o muerte, Sigal y Verón, (1988): 210-214.
} 
oficialista alimentaba esa tensión. La posibilidad de quedar fuera del parlamento daba argumentos al sector más claramente antiperonista del radicalismo, que medía sus opciones entre la abstención y la asonada militar. Por eso, no resulta sorprendente que, tal como hemos visto, en pleno debate apareciera una nueva iniciativa del bloque oficialista destinada a asegurar la presencia de al menos 10 diputados opositores. Sin embargo, la aplicación del sistema reveló que las dificultades no iban a terminarse con esta medida.

\section{Conclusión}

El sistema de circunscripciones uninominales fue utilizado en dos ocasiones en la historia electoral argentina. Sin embargo, hemos tratado de mostrar cómo la apelación a un mismo sistema, tuvo sin embargo objetivos políticos inmediatos y de largo plazo muy diferentes.

En el caso de la reforma de 1902, en medio de un clima político dominado por el imperativo reformista, tuvo como objetivo esencial provocar una regeneración integral de la política estableciendo unas bases renovadas de representación. Así, la promoción de intereses socioeconómicos a los que se concebía existentes en una dimensión local, debía no solo terminar con la crisis de representatividad que se imputaba a la clase política, sino que además el cierre de ese hiato debía también producir una renovación de esa misma clase. Por otra parte, era la propia diversidad del tejido social del país el que devendría, en el seno del Parlamento, en pluralismo político. De esta manera, la ley se haría cargo de otro imperativo del momento.

En 1951, y pese a algunas referencias al antecedente de 1902, los objetivos fueron muy diferentes. Ningún diagnóstico crítico precedió a su aprobación, por el contrario, la representación del pueblo, al que se asociaba con una voz unánime que era indistintamente nacional y peronista, se imaginaba encarnada de modo transparente y virtuoso en la figura del conductor. En este caso, se trataba de construir un Congreso acorde con esta concepción de la democracia: un parlamento casi unánime en el que, por otra parte, cada uno de los diputados sería elegido en primer lugar por el conductor y luego plebiscitado por el pueblo.

En ambos casos, por razones tan diferentes como lo habían sido sus objetivos, las reformas fracasaron y abrieron el camino para sendas reformas. En el primer caso, la de 1912 que instauró el régimen de ma- 
yoría y minoría; en el segundo, la de 1962 que introdujo el sistema de representación proporcional que aún hoy rige nuestro sistema electoral.

\section{Bibliografía}

AELO, Oscar y Nicolás QUIROGA, (2006), «Modelos en conflicto. El Partido Peronista en la provincia de Buenos Aires, 1947-1955». En:Estudios Sociales, № 30, año XVI.

AJMECHET, Sabrina, (2012), «El peronismo como momento de reformas (1946-1955)». En:Revista SAAP, Buenos Aires, Vol 6, N 2.

AJMECHET, Sabrina, (2015a), «La ley electoral argentina de 1951: un análisis sobre las concepciones políticas del peronismo» enHistoria Online Actual [Enlínea], N 35, Puesto en línea en Otoño 2014http:/ /www.historia-actual.org/Publicaciones/index.php/haol/article/ view/965 [último acceso: 8/01/2016].

AJMECHET, Sabrina, (2015b), Las transformaciones en el sistema electoral y las nuevas concepciones de la politica en el peronismo (1946-1955), Tesis doctoral inédita.

ALONSO, Paula, (2010), Jardines secretos, legitimaciones públicas. El partido Autonomista Nacional y la politica argentina de fines del siglo XIX. Buenos Aires: Edhasa.

BIAGINI, Eugenio, (1988), «Rappresentanza virtuale e democracia di massa: i paradossi della Gran Bretagna vittoriana». En:Quaderni Storici, $\mathrm{N}^{\mathrm{O}} 69$.

BOTANA, Natalio, (1985), El orden conservador. La politica argentina entre 1880 y 1916. Buenos Aires: Sudamericana.

CASTRO, Martín, (2012), El ocaso de la República oligárquica. Poder, politica y reforma electoral (1898-1912). Buenos Aires: Edhasa.

DA ORDEN, Liliana y Julio MELÓN PIRRO (Comp.), (2011), Organización política y Estado en tiempos del peronismo. Rosario: Prohistoria.

DE PRIVITELLIO, Luciano, (2009), «Representación política, orden y progreso. La reforma electoral de 1902». En:Politica y Gestión, Vol 9, Universidad Nacional de San Martín.

DE PRIVITELLIO, Luciano, (2011), «Las elecciones entre dos reformas: 1900-1955». En: TERNAVASIO,Marcela, SABATO,Hilda, 
DE PRIVITELLIO, Luciano y PERSELLO,Ana Virginia,Historia de las elecciones en la Argentina. Buenos Aires: El Ateneo.

DE PRIVITELLIO, Luciano, (2011), «Los límites de la abstracción: individuo, sociedad y sufragio femenino en la reforma constitucional de San Juan (1927)». En: Polhis, Boletín bibliográfico, Programa Buenos Aires de Historia política, No 7.

DE PRIVITELLIO, Luciano, (2012), «¿Qué reformó la reforma? La quimera contra la máquina y el voto secreto y obligatorio». En:Estudios Sociales, año XXII, segundo semestre, Santa Fe, Universidad Nacional del Litoral.

DE PRIVITELLIO, Luciano, (2013), «De igualdades y desigualdades: elecciones y poder en el imaginario político argentino» en Ciencias Sociales. Revista de la Facultad de Ciencias Sociales UBA, $\mathrm{N}^{\circ} 84$.

DE PRIVITELLIO, Luciano y PERSELLO, Ana Virginia, (2009), «La Reforma y las reformas: la cuestión electoral en el Congreso (1912-1930)» en BERTONI,Liliana y DE PRIVITELLIO,Luciano (Comps.) Conflictos en Democracia. La vida politica argentina entre dos siglos. Buenos Aires: Siglo XXI.

FERNANDEZ VEGA, José, (2005), Las guerras de la politica. Clausewitz de Maquiavelo a Perón. Buenos Aires: Edhasa.

GARCÍA SEBASTIANI, Marcela, (2005), Los antiperonistas en la Argentina peronista. Radicales y socialistas en la política argentina entre 1943 y 1951. Buenos Aires: Prometeo.

GARZÓN ROGÉ, Mariana, (2012), «Prácticas políticas en la construcción del Partido Peronista. Mendoza 1946-1948». En:Estudios Sociales, $\mathrm{N}^{\mathrm{O}} 42$.

GERCHUNOFF, Pablo y ANTUNEZ, Damián,(2002), «De la bonanza peronista a la crisis de desarrollo», en TORRE,Juan Carlos (Comp.). Los años peronistas (1943-1955). Buenos Aires: Sudamericana.

GONZÁLEZ, Joaquín V., (1903),La reforma electoral argentina. Buenos Aires: Imprenta Didot.

HOBSBAWM, Eric, (1994),Historia del Siglo XX (1914-1991). Barcelona: Crítica.

LUNA, Félix, (2000), Perón y su tiempo II. La comunidad organizada 1950-1952. Buenos Aires: Sudamericana. 
MACKINNON, Moira, (2002), Los años formativos del Partido Peronista (1946-1950). Buenos Aires: Instituto Di Tella-Siglo XXI.

MICHAUD, Éric, (2009), La estética nazi. Un arte de la eternidad. Buenos Aires: Adriana Hidalgo.

MORGAN, Edmund, (2006), La invención del Pueblo. El surgimiento de la soberania popular en Inglaterra y Estados Unidos. Buenos Aires: Siglo XXI.

MOSSE, George, (2005), La nacionalización de las masas. Simbolismo politico y movimientos de masas en Alemania desde las guerras napoleónicas al Tercer Reich. Buenos Aires: Siglo XXI.

MUSTAPIC, Ana María, (1984), «Conflictos institucionales durante el primer gobierno radical: 1916-1922». En:Desarrollo Económico, Vol. 24, No 93.

PADOÁN, Marcelo, (2002), Jesús, el templo y los viles mercaderes. Un examen de la discursividad yrigoyenista. Buenos Aires: Universidad Nacional de Quilmes.

PERSELlO, Ana Virgina, (2000), «Acerca de los partidos políticos, 1890-1943». En:Anuario IEHS, $\mathrm{N}^{\circ} 15$.

PERSELLO, Ana Virginia, (2004), El partido radical. Gobierno y oposición, 1916-1943, Buenos Aires: Siglo XXI.

PERSELLO, Ana Virginia y Luciano DE PRIVITELLIO, (2009), «La Reforma y las reformas: la cuestión electoral en el Congreso (19121930)». En: BERTONI, Lilia Ana y DE PRIVITELLIO,Luciano (Comps.). Conflictos en Democracia. La vida politica argentina entre dos siglos. Buenos Aires: Siglo XXI.

PITKIN, Hanna Fenichel, (1985), El concepto de representación. Madrid: Centro de estudios Constitucionales.

PLOTKIN, Mariano, (1994), Mañana es San Perón. Buenos Aires: Ariel.

POTASH, Robert, (1981), El ejército y la politica en la Argentina, 19451962. Buenos Aires: Sudamericana.

PROL, Mercedes, (2012), Estado, movimiento y partido peronista. La ingeniería institucional en Santa Fe, 1943-1955. Buenos Aires: Siglo XXI.

ROMANELLI, Rafaelle, (1997), «Sistemas electorales y estructuras sociales. El siglo XIX europeo». En: FORNER, Salvador,Democracia, elecciones y modernización en Europa. Siglos XIX y XX. Madrid: Cátedra. 
ROSANVALLON, Pierre, (2002), Por una historia conceptual de lo politico. México: Fondo de Cultura Económica.

ROSANVALLON, Pierre, (2006), La democracia inconclusa. Historia de la soberania del pueblo en Francia. Bogotá: Taurus.

ROSANVALLON, Pierre, (2007), La consagración del ciudadano: Historia del sufragio universal en Francia. México: Instituto Mora.

SABATO, Hilda, (2009), «El pueblo uno e indivisible. Prácticas políticas del liberalismo porteño» en BERTONI, Lilia Ana y DE PRIVITELLIO, Luciano (Comps.), Conflictos en democracia. La vida politica en la Argentina entre dos siglos. Buenos Aires: Siglo XXI.

SABATO, Hilda y Marcela TERNAVASIO, (2011), «El voto en la República. Historia del sufragio en el siglo XIX». En:TERNAVASIO, Marcela, SABATO, Hilda DE PRIVITELLIO,Luciano y PERSELLO, Ana Virginia,Historia de las elecciones en la Argentina. Buenos Aires: El Ateneo.

SÁENZ PEÑA, Roque, (1952), «La quimera y la máquina» en La reforma electoral y temas de politica internacional americana. Buenos Aires: Raigal.

SCHMITT, Carl, (1990), Sobre el Parlamentarismo. Madrid: Tecnos.

SIGAL, Silvia y Eliseo VERÓN, (1988),Perón o Muerte. Los fundamentos discursivos del fenómeno peronista. Buenos Aires: Hyspamérica.

TERNAVASIO, Marcela, Hilda SABATO, Luciano DE PRIVITELLIO y Ana Virginia PERSELLO, (2011), Historia de las elecciones en la Argentina. Buenos Aires: El Ateneo.

ZIMMERMANN, Eduardo, (1995), Los liberales reformistas. La cuestión social en la Argentina 1890-1916. Buenos Aires: Sudamericana. 